\title{
Monitoring the Shear Fatigue Response of Reinforced Concrete Beams Subjected to Moving Loads using Digital Image Correlation
}

\author{
Suryanto, B. ${ }^{*}$ and Staniforth, G. ${ }^{2}$
}

\begin{abstract}
A series of three reinforced concrete beams without shear reinforcement were tested to failure under a centre-span monotonic load, a centre-span pulsating load, and a stepwisemoving pulsating load. During each experiment, load-deflection response was continuously monitored and at several stages during the experiment, the load was briefly stopped for crack observations. In addition to this manual crack mapping, more detailed crack mappings were undertaken using the digital image correlation (DIC) technique, employing the open-source DIC software Ncorr. It was shown that while the three beams exhibited a similar mode of failure (i.e. shear), each beam displayed a rather distinctive overall behaviour, particularly with regard to the load-deflection response and the nature of crack initiation and propagation. Results from the DIC analysis are presented to provide direct evidence on the damage progression during the load cycles and discuss the reduced fatigue life exhibited by the beam subjected to stepwise-moving pulsating load.
\end{abstract}

Keywords: Moving load; pulsating; shear; fatigue; DIC; Ncorr.

\section{Introduction}

Shear fatigue has been the subject of investigation by many researchers and engineers in the past decades. Traditionally, these investigations have been undertaken mainly on reinforced concrete beams, with the cyclic load normally applied at the centre of span. This includes the pioneering works by Chang and Kesler [1], and Taylor [2], who tested a series of reinforced concrete beams without shear reinforcement subjected to varying magnitudes of load, and Farghaly [3] and Okamura et al. [4] who were able to quantify the reduction in the magnitude of shear forces resisted by the concrete under fatigue loading. To better reproduce the influence of moving load on fatigue life, Matsui [5,6] and Perdikaris and Beim [7] led independent experimental studies in Japan and in the US, investigating, respectively, the behaviour of full and 1/6.6-scale reinforced concrete deck models under stationary pulsating and moving loads. They found that a moving load had a more damaging effect than a pulsating load. It was observed that the crack patterns of the bridge deck models subjected to moving loads resembled more closely the crack patterns observed on real bridge decks, characterised typically by a grid-like crack pattern following the orthotropic arrangement of longitudinal reinforcement embedded inside the bridge deck model (see, for example, Figure 1 [5]).

\footnotetext{
1,2 Institute for Infrastructure and Environment; School of Energy, Geoscience, Infrastructure and Society; Heriot-Watt University; Edinburgh; UNITED KINGDOM

*Corresponding author: b.suryanto@hw.ac.uk
}

Note: Discussion is expected before June, $1^{\text {st }} 2018$, and will be published in the "Civil Engineering Dimension", volume 21, number 2, September 2019.

Received 25 September 2018; revised 14 January 2019; accepted 22 January 2019.
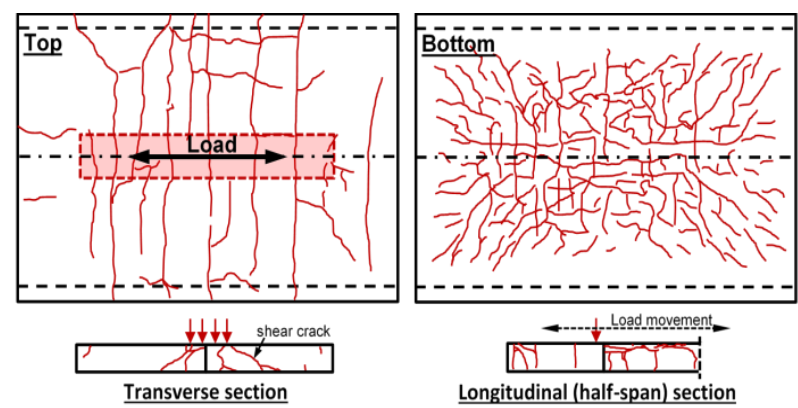

Figure 1. Typical Failure Crack Diagrams for a Bridge Deck Slab Subjected to Moving-wheel Load Cycles. Redrawn from the Diagrams Reported by Matsui in 1984 [5].

To investigate the underlying mechanisms responsible for shear fatigue of reinforced concrete, Maekawa and co-workers developed a nonlinear finite element analysis program for the analysis of reinforced concrete subjected to general loading conditions including fatigue [8]. The software package employs the direct-path integration scheme and incorporates the time-dependent and fatigue constitutive models, all implemented within the smeared, multi-directional fixed-crack scheme. Using this program, it was demonstrated through a comprehensive parametric study that shear transfer on crack interfaces has an important role to play in determining the fatigue life of reinforced concrete elements, particularly when water is present in the crack interfaces $[9,10]$ which agrees with the experimental findings of Gebreyouhannes et al. [11]. Employing the same software package, Gebreyouhannes et al. performed further simulations on shear-critical reinforced concrete beams subjected to pulsating stationary and moving loads [12]. It was found that when a reinforced concrete beam is subjected to moving load, a reduction in fatigue life up to three orders of magnitude, with respect to the expected life under a 
stationary pulsating load, can occur. Gebreyouhannes et al. also mentioned that the underlying mechanisms responsible for fatigue life reduction in beams are different to those normally observed in bridge deck slabs [12]. Despite the difference, Fujiyama and Maekawa [13] found that steel-composite reinforced concrete bridge decks exhibit a reduced fatigue life of comparable order when subjected to moving loads.

The primary objective of this paper is to provide further evidence into the complex response of reinforced concrete when subjected to moving loads. More specifically, this paper aims to provide direct evidence on crack formation and damage evolution under such loading conditions. To this end, the application of low-cost, automated crack mapping system is presented to obtain detailed insights into the behaviour of reinforced concrete beams without shear reinforcement under moving loads. The beamlike element is used to represent part of a bridge deck in which the two-way slab action has lost due to load movement [12]. In this paper, attention is directed to the details of the experimental programme, the load protocol used to produce a moving load, the techniques used to automatically map cracking, the load-deflection response, and the crack formation under moving load. The findings of this study are expected to be beneficial to structural engineers and researchers who require a deeper understanding of the influence of moving load on the shear capacity of reinforced concrete beams; the current study is, however, limited to the response of such members under low-cycle high-amplitude cyclic loading. Currently behaviours under high-cycle low-amplitude fatigue are of renewed interest in the UK as such loading conditions are likely to arise during the design of reinforced concrete bridge slabs and girders for the high speed two (HS2) rail infrastructure.

\section{Experimental Programme}

The experimental programme undertaken involved the testing of three notionally identical reinforced concrete beams with nominal dimensions of $155 \mathrm{~mm}$ (width) $\times 300 \mathrm{~mm}$ (depth) $\times 2200 \mathrm{~mm}$ (length). All beams were reinforced with three $16 \mathrm{~mm}$ longitudinal bars at an effective depth of $257 \mathrm{~mm}$. No top and shear reinforcement were provided to separate out the effects of these variables and to better capture the true impact of moving loads on damage progression in the concrete. The elevation and crosssection details of the beams are presented in Figure 2.

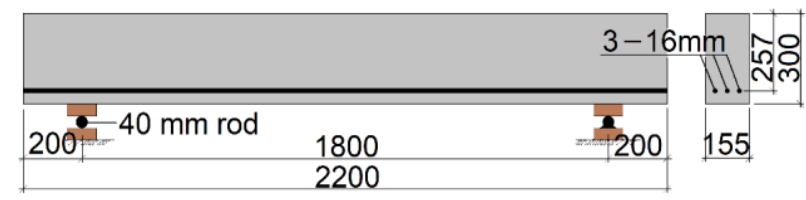

Figure 2. Elevation and Cross-section Details. All Dimensions are in $\mathrm{mm}$.

\section{Beam Fabrication and Curing}

A locally sourced ready-mix concrete with a target mean strength of $35 \mathrm{MPa}$ and a slump of $60 \mathrm{~mm}$ was used to fabricate the three beam specimens. The binder used in the concrete was a blend of Portland cement CEM I 52.5N in accordance with BSEN197-1 [14] and ground granulated blast furnace slag in accordance with BSEN15167-1 [15] at a ratio of 1:1. The water-to-binder ratio was 0.50 . A well-graded basalt aggregate sourced locally with a maximum size of $20 \mathrm{~mm}$ was used, mixed together with a wellgraded sand with a maximum size of $4 \mathrm{~mm}$ which satisfies the requirements of BS EN12620 [16]. To achieve the required consistency, a superplasticiser (BASF MasterGlenium Sky 920) was added into the concrete mix at an amount of $0.55 \%$ by binder weight.

Upon delivery, the concrete was discharged from a ready-mix truck directly into pre-assembled steel frameworks via a telescopic chute mounted at the back of the truck. The pour was made in two layers, with each layer compacted using a vibrating rod to ensure adequate compaction (see Figure 3). Immediately after compaction, the top surface of the beams was levelled and then covered with a polyethylene sheet. The beams were then wetted daily for further 6 days before the framework being removed for the remaining 35 days. During the latter period, the beams were stored under a polyethylene sheet and wetted twice per week. Daily mean laboratory temperature ranged between 6$13^{\circ} \mathrm{C}$. Testing was carried out between 42 and 54 days after casting. The mean compressive strength of the concrete at 49 days was $41.6 \mathrm{MPa}$; this value has been converted from the mean cube compressive strength which was determined on three $100 \mathrm{~mm}$ cubes. The modulus of elasticity and the mean yield strength of the reinforcing bars were $200 \mathrm{GPa}$ and $575 \mathrm{MPa}$, respectively.

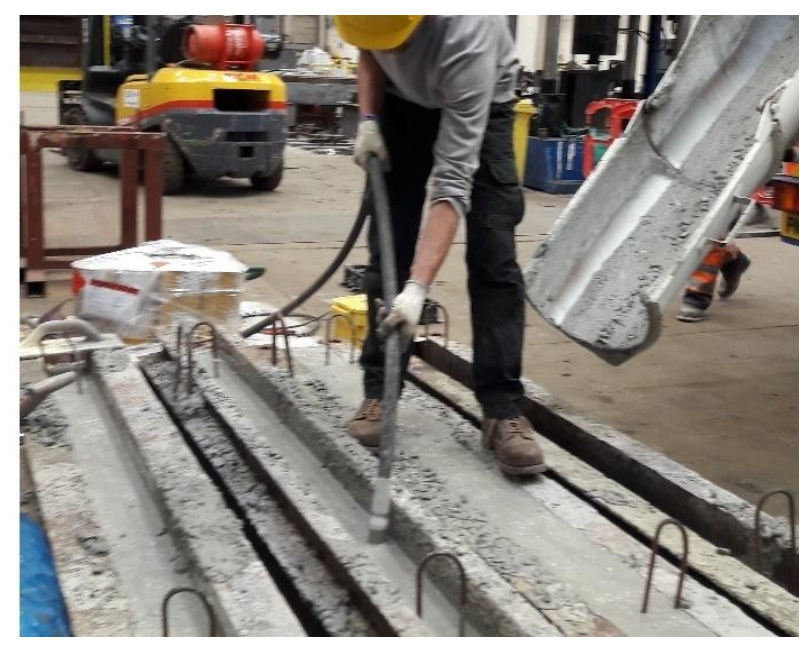

Figure 3. Concrete Compaction During Casting 


\section{Test Setup}

Figure 4 displays the overall test setup used in the experimental programme, with the tests undertaken within a servo-controlled Losenhausen $2,000 \mathrm{kN}$ testing machine [17]. In each test, the beam was first positioned below the crosshead of the machine and supported at a distance of $200 \mathrm{~mm}$ from both ends to give an overall span of $1,800 \mathrm{~mm}$. Beams 1 and 2 were both subjected to a concentrated load at the centre span. The load for Beam 1 was applied in a monotonic manner under displacement control at a constant rate of $0.2 \mathrm{~mm} / \mathrm{min}$, while the load for Beam 2 was applied in a cyclic manner under force control between $14 \%$ and $78 \%$ of the static capacity of Beam 1. The concentrated load was applied through a $100 \times 150 \times 40$ (thick) $\mathrm{mm}$ steel plate and a $300 \mathrm{kN}$ spherical head load cell. Beam 3 was subjected to the same magnitude of load applied to Beam 2; in this beam, however, the load was applied in sequence at five different locations along the beam, each spaced $250 \mathrm{~mm}$ apart. This is detailed in the following section.

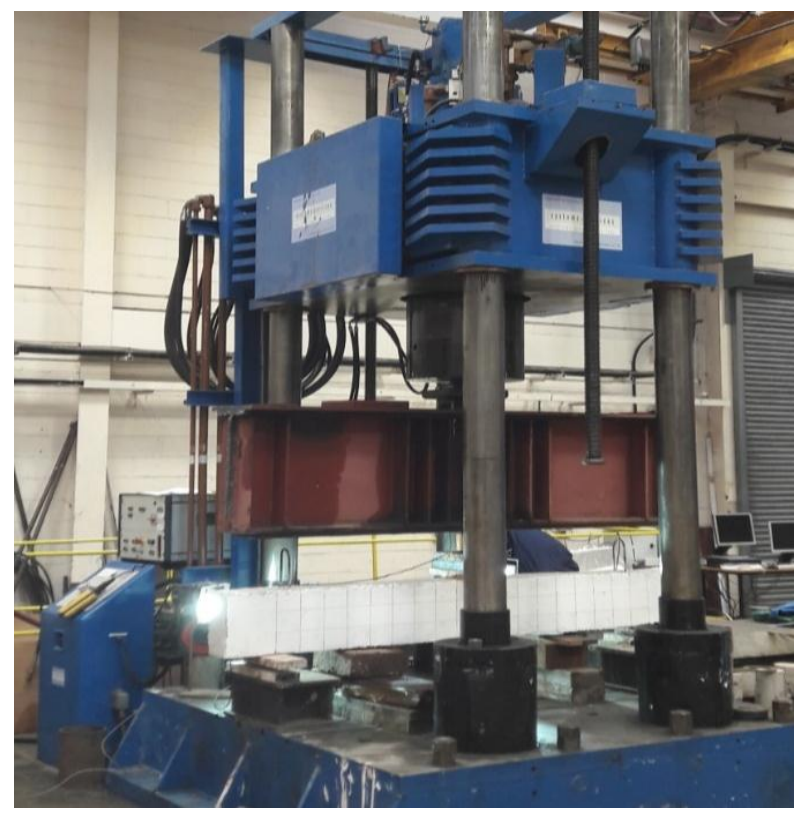

Figure 4. Test Setup Showing Beam 3 during the Preparatory Stage.

\section{Moving Load Protocol}

To enable the point load to be applied at five different locations along the beam using only one actuator, the test configuration depicted in Figure 5 was employed. In this setup, a heavily-stiffened steel I section with nominal dimensions of $670 \times 240 \times$ 2,200 (long) $\mathrm{mm}$ was used. Prior to testing, the steel beam was connected to the upper hydraulic jaw of the testing machine and served as a spreader beam during testing. Below this beam, two $300 \mathrm{kN}$ spherical head load cells were used at a time to ensure stability and equilibrium.

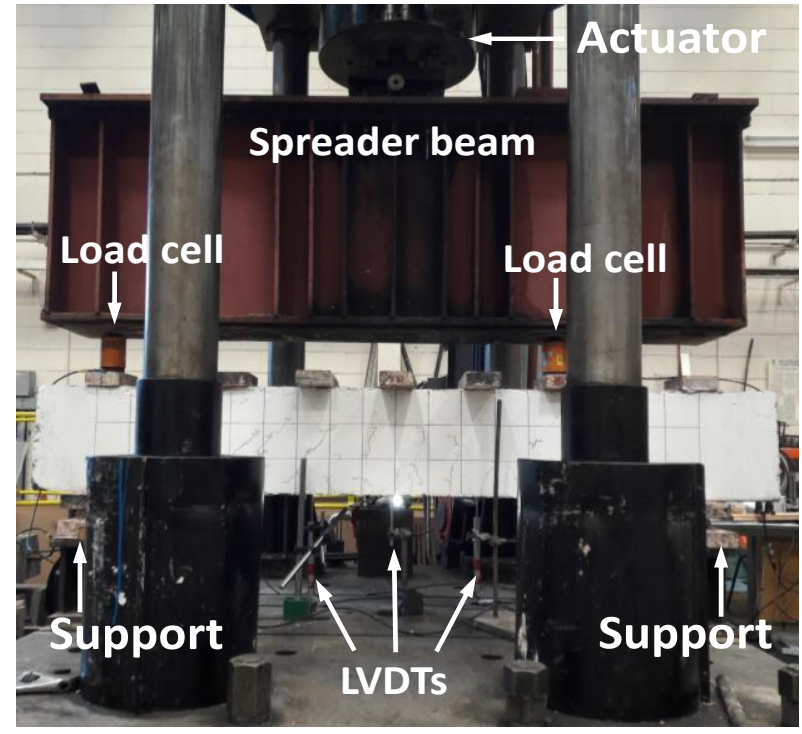

Figure 5. Test Setup Showing the State of Beam 3 at the North Side during Testing. The Supports are Partially Blocked by the Front Columns.
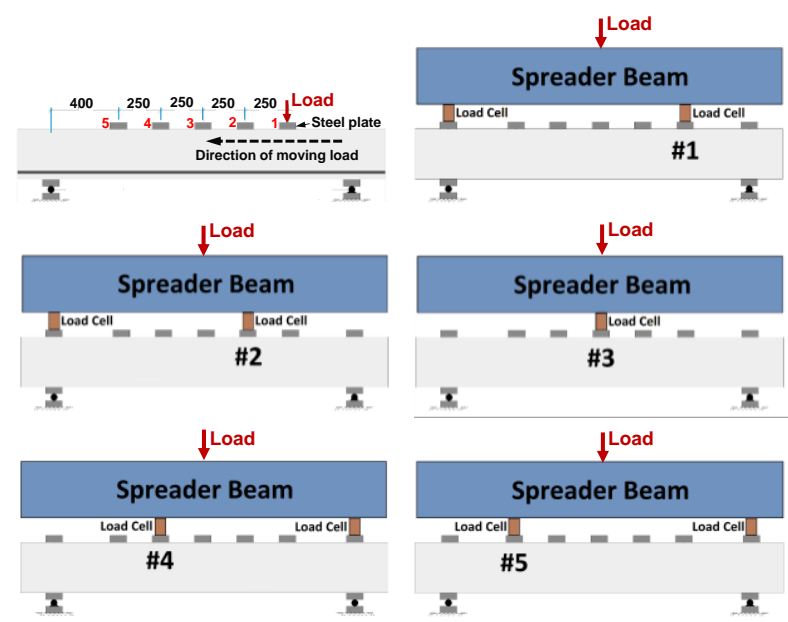

Figure 6. Moving Load Test Protocol Employed in the Test Programme.

To simulate a moving load travelling on the top of the beam from the right to the left-hand side using one single actuator without the need for performing costly alterations to the testing machine, the following test protocol was implemented:

(i) Loading was first initiated by placing one of the load cells at Load Point 1 and the other load cell directly above the left support, as indicated in the schematic in Figure 6. The load was then applied in a displacement control manner to a load of approximately $78 \%$ of the capacity of Beam 1 before being fully unloaded.

(ii) The actuator was then raised a few $\mathrm{mm}$ to lift the spreader beam, allowing the load cell on the right to be moved to Load Point 2 while the other load cell was kept in place. The beam was then subjected to same load amplitude.

(iii) Following (ii), the spreader beam was then raised once again to move the load cell on the 
right to Load Point 3 at the centre span. At this stage, the other load cell was temporarily removed, provided that the centre span of the beam aligned fully with the centre of the actuator. The same amplitude of load was then applied.

(iv) The spreader beam was lifted once again to enable the two load cells to be positioned at Load Point 4 and the top of the right support. The load was then applied as before.

(v) Finally, after the spreader beam being lifted, the load cell on the left was moved to Load Point 5 while the other load cell was kept in place. The same amplitude of loading was then applied to complete one full loading passage.

Steps (i) - (v) were repeated until the beam reached its ultimate stage. To simplify this laborious process, seven steel plates with a width of $100 \mathrm{~mm}$ and a thickness of $40 \mathrm{~mm}$ were pre-arranged at all load points as depicted in Figures 5 and 6; as such, it was only necessary to move the load cell(s) during testing. Hereinafter this load protocol is referred to as a step-wise moving load.

\section{Instrumentation and Crack Mapping}

A precision linear variable displacement transducer (LVDT) was placed under the beam and aligned vertically under each load point using a magnetic holder (for clarity, see some examples in Figure 5). These transducers and all the load cells used were connected to a data acquisition system. The data were logged at a rate of $2 \mathrm{~Hz}$.

During testing, loading was briefly stopped to visually assess cracking on the North side of the beam. In addition to this manual crack mapping, more detailed crack mappings were undertaken using the low-cost system recently proposed by the authors $[18,19]$. The system employed comprised an ordinary 18.4MP Nikon $1 \mathrm{~J} 4$ digital camera and a smartphone for image collection, and an open-source DIC software Ncorr [20], which was used to process the images collected during testing. The camera was mounted on a tripod at a distance approximately 600 $\mathrm{mm}$ from the South surface of the beam and to avoid inadvertent camera movement, images were collected remotely using an Iphone $4 \mathrm{~S}$ via Nikon wireless mobility utility application. A DC power supply was used to provide continuous power supply to the camera throughout the test programme.

Once the beam had been set into its position for testing, both the North and South facing surfaces were painted white using emulsion paint. Once the paint had dried, highly contract speckled patterns were then created on the South surface of the beam using a dotted-effect black spray paint. It is worth nothing that using this special paint, it was possible to produce a high-quality speckle pattern (in terms of spacing, size, and randomness) over a relatively large surface area $\left(300 \times 2200 \mathrm{~mm}^{2}\right)$ in a short period of time (generally less than five minutes). An example of the speckle pattern over an area of approximately $100 \times 100 \mathrm{~mm}$ square is displayed in Figure 7. To minimize the shadow from the surrounding test equipment, three LED lights were used. At the time of testing, only alternating current LED lights were available which resulted into undesirable flickering issues. This limitation will be addressed in a further study.

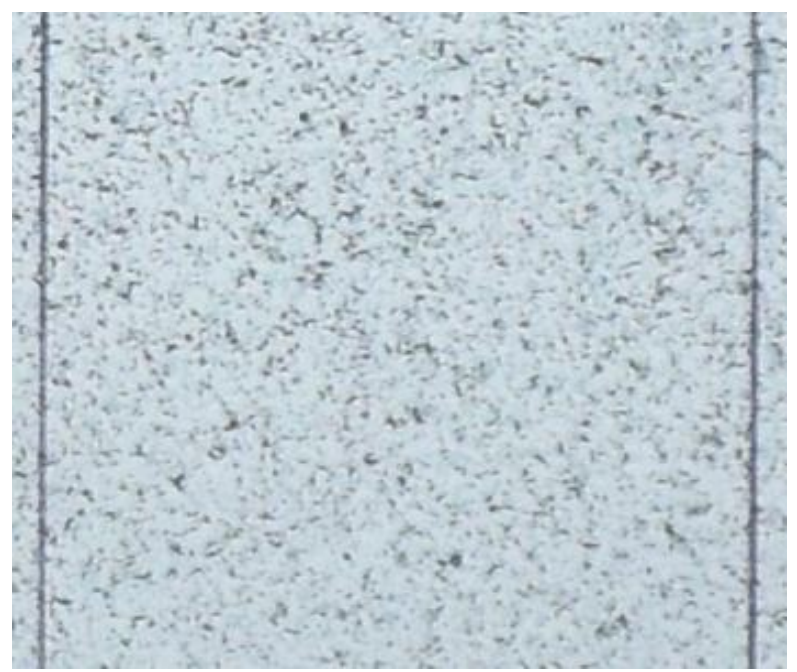

Figure 7. Random Speckled Pattern Generated on the Beam Surface. The Distance of the Vertical Gridlines is 100 $\mathrm{mm}$.

The acquired images were processed using an opensource DIC software Ncorr [20] in order to produce longitudinal strain plots at various stages of loading during the load cycles. These plots are particularly suited for capturing the development and propagation of concrete cracks oriented vertically. However, as some of the cracks in the beams did not align vertically (i.e. the diagonal shear crack), it would be ideal to plot the principal tensile strain fields. However, this would require the development of a post-processing extension which at the time of writing is still under development; this would, therefore, form the scope for future study.

\section{Test Results and Discussion}

\section{Load-deflection Responses}

The load-deflection responses for Beams 1, 2, and 3 are presented in Figures 8(a) and (b). Due to the large number of load cycles/passages experienced by Beams 2 and 3 (particularly Beam 2), the responses of these beams are only shown at selected numbers 
of load cycles/passages for reasons of clarity. It is apparent from Figure 8(a) that Beam 1 exhibits a typical response of shear-critical beam, characterised primarily by a sudden loss in load carrying capacity upon failure. This occurred suddenly when the load reached $110 \mathrm{kN}$, which is approximately 30\% higher than the load capacity predicted by SNI 2847:2013 $[21,22]$. Failure was brittle resulted from sudden crack propagation at one side of the beam upward to the point of load application and downward to the support along the bottom reinforcement.
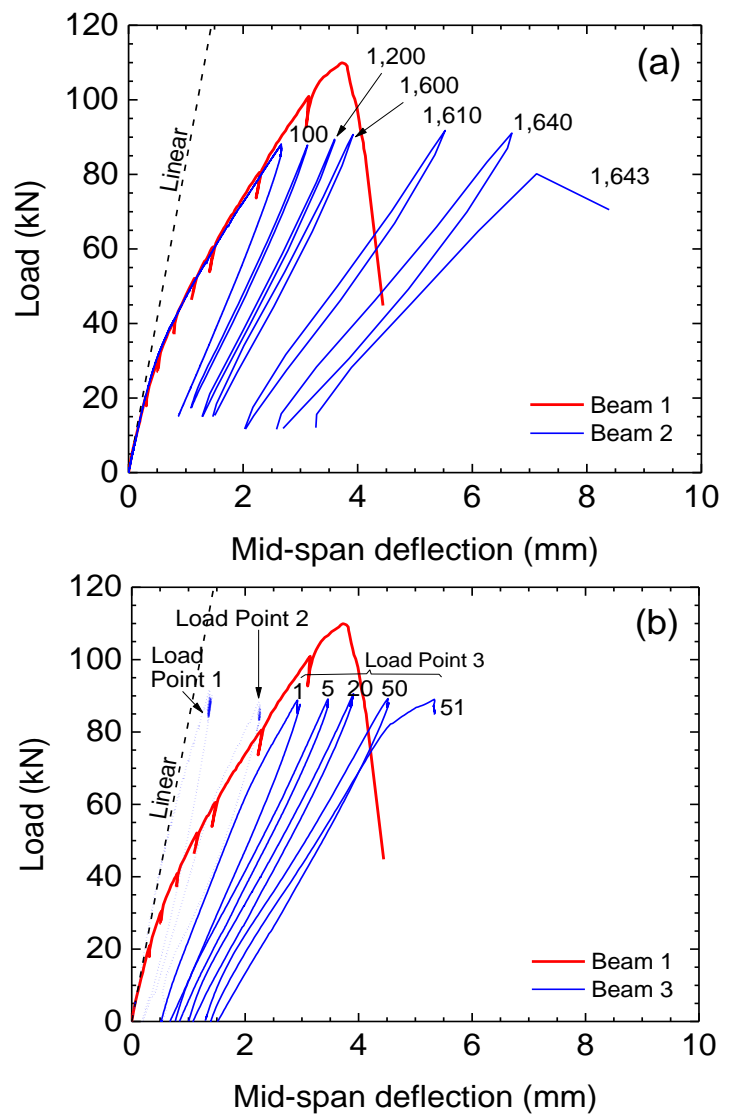

Figure 8. Load-deflection Response of All Beams Tested.

With reference to Figure 8(a), it is apparent that the response of Beam 2 during the first cycle is comparable to that of Beam 1. However, it is interesting to note that when subjected to further load cycles, Beam 2 exhibits progressive reductions in beam stiffness, particularly over the initial 100 cycles. This continues throughout the cycles which indicate damage progression. Both the maximum and residual deflections of the beam also notably increase and are cumulative with increasing number of load cycles which is indicative of damage accumulation. When the applied load reached approximately $1.6 \mathrm{k}$ cycles, there was a sudden formation and propagation of diagonal shear crack, causing the beam deflection to increase significantly. At 1,643 cycles, the beam eventually split into two parts in a very brittle manner.
By comparing the load-deflection response of Beam 3 in Figure 8(b) to that of Beam 2 in Figure 8(a), it is clear that moving load introduces a far more damaging effect than the pulsating load. The evidence for this can be particularly seen from the fatigue life of Beam 3 which is almost two orders of magnitude lower than that of Beam 2 (i.e. 51 passages vs $1.6 \mathrm{k}+$ cycles). The fact that moving load has the effect of accelerating fracture and damage processes within the concrete can be traced from the individual hysteresis presented in Figure 8(b). Beam 3 is seen to exhibit a significant residual deflection upon unloading, so as displaying an open hysteresis, most likely due to the formation and propagation of concrete cracking during one load passage. This contrasts with the hysteresis of Beam 2 which generally exhibits a rather close hysteresis (as the beam is loaded and then unloaded, it virtually returns to its original deflection value). Furthermore, the accelerated damage exhibited by Beam 3 at each load passage can also be attributed to the fact that as the applied load moves from Load Points 1 to 5, it has the effect of constantly changing the moment-toshear ratio (and hence the principal stress orientations at various locations along the beam) [23]. With regards to the pre-existing cracks, the change in principal stress orientations would cause shear stresses to develop across these cracks [23-25] and change sign as the load passes these cracks. It is anticipated that this crack shear reversal would cause two crack surfaces to slide against each other and widen thereby accelerating deterioration. In addition to these two mechanisms, the reduction in fatigue life could also be associated with the increase in shear magnitude as the load moves toward the support [12], although the shear capacity can also be expected to increase as the shear span-to-depth ratio decreases. More detailed assessment on the underlying mechanisms influencing the development and propagation of cracks and the reduction in fatigue life will be reported in a future publication.

\section{Longitudinal Strain Profiles}

To better understand the progress of damage in the test beams, the longitudinal strain profiles obtained from the DIC analysis are presented in Figures 9 and 10 . However, given the large amount of results populated from the analysis, only the longitudinal strains of Beams 1 and 3 at selected load levels and passages are presented. From Figure 9, it is evident that the initial cracking in Beam 1 was predominantly flexural. These cracks quickly extended over half the beam depth as the load increased. Some diagonal cracks initiated during the later loading stages and were an extension of the flexural cracks that had developed early. At failure, the top of the critical crack extended to the point of load application, while at the other end propagated downward until it reached the tension reinforcement and continued parallel to the reinforcement, forming a S- 
shape crack pattern. This is in line with the failure crack pattern typically found in a shear critical beam with a shear span-to-an-effective-depth ratio of approximately 3 .

With reference to Figure 10, it is interesting to observe that in general terms, the crack pattern of Beam 3 takes the same form of that of Beam 1 with respect to the overall pattern and spacing, although the cracks in Beam 3 are seen to develop over a wider area. On closer examination, however, it is interesting to note that the individual crack developed in Beam 3 took a more undulating path than that in Beam 1 and this is likely due to the constant change in principal stress direction as the load was moved from Load Points 1 to 5. As such, during the loading passage, the pre-existing cracks would propagate in different orientations and thereby exhibiting rotating crack tips. It is also interesting to note during the first passage that while the location of the cracks exhibiting greater crack widths essentially follows the location of the applied load, this is not the case in the following cycles as most of the cracks remained open while the load had moved to other locations along the beam. Another interesting feature from the strain plots presented in Figure 10 relates to the progressive development of the diagonal crack over the left span which could be described as shear flexural in nature. It is clear that failure was initiated by two flexural cracks which then developed into a single inclined crack over the mid-height of the web region during the load passage. This occurred when the load was applied at the centre span (Load Point 3) during the $51^{\text {st }}$ load passage.
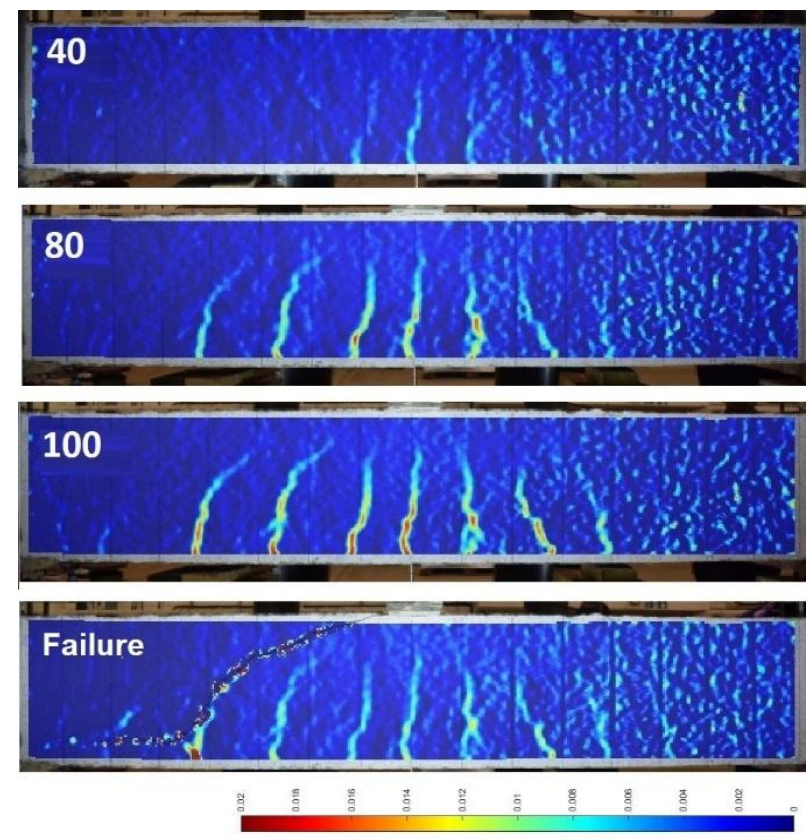

Figure 9. Longitudinal Strain Profiles of Beam 1 Obtained from the DIC Analysis. Numbers Shown Indicate the Load Level in $\mathrm{kN}$. Patches on the Right are Due to Lighting Issues.

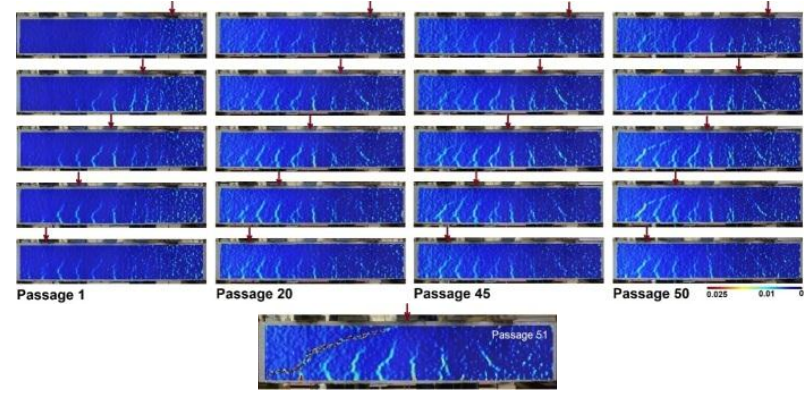

Figure 10. DIC Longitudinal Strain Profiles for Beam 3. Patches on the Right are Due to Lighting Issues.

\section{Concluding Remarks}

This paper highlights the application of a low-cost, automated crack mapping technique to provide direct evidence on the behaviour and crack patterns of shear-critical reinforced concrete beams. Through a series of investigations, it has been demonstrated that moving load causes a far more damaging effect than a stationary pulsating load. More specifically, moving load is shown to result in a greater rate of increase in beam deflection, a greater accumulation of residual beam deflections, a more complex crack pattern, and a greater extent of damage with increasing number of load cycles/passages. At a load amplitude of approximately $78 \%$ of the static capacity, the shear fatigue life of a reinforced concrete beam without shear reinforcement is shown to decrease by almost two orders of magnitude, from approximately $1.6 \mathrm{k}+$ cycles to only 51 load passages. This is of considerable significance because in most situations loading is applied in a non-monotonic and non-stationary manner. The evidence gathered from this study will be subsequently used to investigate the underlying mechanisms exhibited by the three beams. Future study will also be directed toward investigating the influence of load amplitude and speed.

\section{Acknowledgements}

The authors wish to acknowledge the support of the School of Energy, Geoscience, Infrastructure and Society at Heriot-Watt University for placing the facilities of the School at their disposal. They also wish to acknowledge the help of Martin Aitken and Paul Miller for assistance in the experimental work, and to thank Dr Asdam Tambusay for many helpful discussions regarding the DIC analysis. This article was part of the MEng project of George Staniforth.

\section{References}

1. Chang, T. S., Kesler, C. E., Fatigue Behavior of Reinforced Concrete Beams, Journal Proceedings of the American Concrete Institute, 55(8), 1958, pp. 245-254. 
2. Taylor, R., Discussion of a Paper by Chang, T. S. and Kesler, C. E., Journal Proceedings of the American Concrete Institute, 55(14), 1959, pp. 1011-1015.

3. Farghaly, S. A., Shear Design of Reinforced Concrete Beams for Static and Repeated Loads, PhD Thesis, University of Tokyo, 1979.

4. Okamura, H, Farghaly, S.A., and Ueda, T., Behaviors of Reinforced Concrete Beams with Stirrups Failing in Shear under Fatigue Loading, Proceedings of the Japan Society of Civil Engineers, 308, 1981, pp. 109-122.

5. Matsui, S., Study on Fatigue and Design for Highway Concrete Decks, PhD Thesis, Osaka University, 1984.

6. Matsui, S., Fatigue Strength of RC Slabs of Highway Bridge by Wheel Running Machine and Influence of Water on Fatigue, Proceedings of Japan Concrete Institute, 9(2), 1987, pp. 627632.

7. Perdikaris, P.C., Beim, S., RC Bridge Decks under Pulsating and Moving Load, ASCE Journal of Structural Engineering, 114(3), 1988, pp. 591-607.

8. Maekawa, K., Toongoenthong, K., Gebreyouhannes, E., and Kishi, T., Direct Path-integral Scheme for Fatigue Simulation of Reinforced Concrete in Shear, Journal of Advanced Concrete Technology, 4(1), 2006, pp. 159-177.

9. Maekawa, K., Gebreyouhannes, E., Mishima, T., and An, X., Three-dimensional Fatigue Simulation of RC Slabs under Traveling Wheel-type Loads, Journal of Advanced Concrete Technology, 4(3), 2006, pp. 445-457.

10. Maekawa, K., Ishida, T., Chijiwa, N., Fujiyama, C., Multiscale Coupled-Hygromechanistic Approach to the Life-Cycle Performance Assessment of Structural Concrete, ASCE Journal of Materials in Civil Engineering, 27(2), 2013, pp. A4014003.

11. Gebreyouhannes, E., Kishi, T., and Maekawa, K., Shear Fatigue Response of Cracked Concrete Interface, Journal of Advanced Concrete Technology, 6(2), 2008, pp. 365-376.

12. Gebreyouhannes, E., Chijiwa, N., Fujiyama, C., and Maekawa, K., Shear Fatigue Simulation of RC Beams subjected to Fixed Pulsating and Moving Loads, Journal of Advanced Concrete Technology, 6(1), 2008, pp. 215-226.

13. Fujiyama, C., Maekawa, K., A Computational Simulation for the Damage Mechanism of Steelconcrete Composite Slabs under High Cycle Fatigue Loads, Journal of Advanced Concrete Technology, 9(2), 2011, pp. 193-204.

14. BS EN 197-1:2011, Cement: Composition, Specifications and Conformity Criteria for Common Cements, British Standards Institution, 2011.
15. BS EN 15167-1:2006, Ground Granulated Blast Furnace Slag for Use in Concrete, Mortar and Grout. Definitions, Specifications and Conformity Criteria, British Standards Institution, 2006.

16. BS EN 12620:2013, Aggregates for Concrete, British Standards Institution, 2013.

17. Hasnayn, M. M., McCarter, W. J., Woodward, P. K., Connolly, D. P., and Starrs, G. Railway Subgrade Performance during Flooding and the Post-flooding (Recovery) Period, Transportation Geotechnics, 11, 2017, pp. 57-68.

18. Suryanto, B., Tambusay, A., and Suprobo, P., Crack Mapping on Shear-critical Reinforced Concrete Beams using an Open Source Digital Image Correlation Software, Civil Engineering Dimension, 19(2), 2017, pp. 93-98.

19. Tambusay, A., Suryanto, B., and Suprobo, P., Visualization of Shear Cracks in a Reinforced Concrete Beam using the Digital Image Correlation, International Journal on Advanced Science, Engineering and Information Technology, 8(2), 2018, pp. 573-578.

20. Blaber, J., Adair, B., and Antoniou, A., Ncorr: Open-Source 2D Digital Image Correlation Matlab Software, Experimental Mechanics, 55(6), 2015, pp. 1105-1122.

21. SNI 2847:2013, Persyaratan Beton Struktural untuk Bangunan Gedung, Badan Standardisasi Nasional, Department of Public Work of Indonesia, 2013.

22. Suryanto, B., Morgan, R., and Han, A.L., Predicting the Response of Shear-critical Reinforced Concrete Beams using Response-2000 and SNI2847: 2013, Civil Engineering Dimension, 18(1),2016, pp. 16-24

23. Suryanto, B., Staniforth, G., Kim, J., Gebreyouhannes, E., Chijiwa, C., Fujiyama, C., and Woodward, P. K. Investigating the Mechanism of Shear Fatigue in Reinforced Concrete Beams subjected to Pulsating and Moving Loads using Digital Image Correlation, Proceedings of the Fourth International Conference on Sustainable Civil Engineering Structures and Construction Materials: Sustainable Structures for Future Generation, 5-7 September 2018, Yogyakarta, Indonesia, in press.

24. Suryanto, B., Nagai, K., and Maekawa, K., Bidirectional Multiple Cracking Tests on HighPerformance Fiber-Reinforced Cementitious Composite Plates, ACI Materials Journal, 107(5), 2010, pp. 450-460.

25. Suryanto, B., Nagai, K., and Maekawa, K., Smeared-crack Modeling of R/ECC Membranes Incorporating an Explicit Shear Transfer Model, Journal of Advanced Concrete Technology, 8(3), 2010, pp. 315-326. 